\title{
Additive effects of Cox-1 and Cox-2 inhibition on breast cancer in vitro
}

\author{
DAVID W. McFADDEN, DALE R. RIGGS, BARBARA J. JACKSON and CYNTHIA CUNNINGHAM \\ Departments of Surgery and Microbiology, P.O. Box 9238, Robert C. Byrd Health Sciences Center, \\ West Virginia University, Morgantown, WV 26506, USA
}

Received March 20, 2006; Accepted May 19, 2006

\begin{abstract}
We hypothesized that combined treatment with Cox-1 and Cox-2 specific inhibitiors would exhibit synergistic effects against breast cancer in vitro. Two human breast cancer cell lines (HTB26, MCF-7) were treated with catechin (Cox-1 inhibitor) or NS398 (Cox-2 inhibitor) at $100 \mu \mathrm{M}$ as both single and combined treatments. Reductions in cell growth were observed in both cell lines at 24 and $72 \mathrm{~h}$ in both single and combined treatments $(\mathrm{p}<0.001)$. Combined treatment produced a significantly greater inhibition as compared to single agents alone. Upon cell cycle evaluation, Cox-1 and -2 antagonism increased $G_{1}$ and $G_{2}$ phase fractions in MCF-7 cells $(p<0.001$ and $p<0.05$ respectively). No additive changes were observed when the two agents were combined. An increase in the $G_{2}$ phase was observed in the HTB26 cells when treated with NS398 alone $(p<0.001)$. However, a decrease in the S-phase was observed when these cells were treated with NS398, as a single agent $(\mathrm{p}<0.01)$ or when the two agents were combined $(\mathrm{p}<0.01)$. The significant and additive effects exhibited by the combination of Cox-1 and -2 inhibitors and their effects on cell cycle suggest that these agents could become an effective treatment modality for carcinoma of the breast.
\end{abstract}

\section{Introduction}

There were $\sim 213,000$ new cases of breast cancer in 2005, with an estimated 40,870 deaths attributed to this cancer. (1). The relative mortality (mortality/incidence) from breast cancer dropped from $25.2 \%$ in 1995 to $19.1 \%$ in 2005 . This decline in relative mortality may be attributed to advances made in detection methods, treatment modalities, and public awareness. Treatment for breast cancer includes surgery, radiation therapy, chemotherapy, and/or hormonal therapy. These therapies are often combined in an attempt to increase the response to

Correspondence to: Dr David W. McFadden, P.O. Box 9238, Department of Surgery, Robert C. Byrd Health Sciences Center, West Virginia University, Morgantown, WV 26506, USA

E-mail: dmcfadden@hsc.wvu.edu

Key words: apoptosis, breast cancer, cell cycle, cell proliferation, Cox- 1 and -2 inhibitors treatment. However, many patients fail to respond to these therapies or present initially with invasive disease. For these patients, new and effective treatment modalities are needed.

Cyclooxygenase (COX) is an important enzyme that catalyzes the conversion of arachidonic acid to prostaglandin. The constitutive Cox-1 isoform is found in most cells and regulates multiple physiological processes. Most commercially available non-steroidal anti-inflammatory drugs (NSAIDS) work by inhibiting the Cox-2 variant, thereby reducing inflammation. Many Cox-2 inhibitors have been shown to demonstrate anti-proliferative and anti-neoplastic properties. In a study of over 80,000 women it was reported that regular users of NSAIDS ( 2 or more tablets a week) had a $21 \%$ reduction in the incidence of breast cancer after 5-9 years and a $28 \%$ decrease after 10 years (2).

We have recently reported in vitro inhibition of cell proliferation by rofecoxib (VIOXX ${ }^{\circledR}$ ), a highly selective CoX-2 inhibitor, in cancers of the esophagus, bladder, prostate and breast (3-5). We have also reported significant inhibitory effects of a Cox-1 specific inhibitor (catechin) on bladder cancer cells in vitro (4). Based on these findings, we hypothesized that the combination of Cox-1 and Cox-2 inhibitory agents would exhibit additive effects against breast cancer in vitro.

\section{Materials and methods}

COX-1 and COX-2 inhibitors. Both catechin (a specific Cox-1 inhibitor derived from green tea) and NS398 (a standard, experimental Cox-2 inhibitor) were obtained from Cayman Chemicals (Ann Arbor, MI). Both inhibitors were suspended to the experimental concentration of $100 \mu \mathrm{M}$, which was chosen from previous studies reported by this laboratory. catechin was dissolved in $100 \%$ ethanol to a concentration of $1 \mathrm{mg} / \mathrm{ml}$ and diluted to a $100-\mu \mathrm{M}$ concentration in tissue culture media. NS398 was dissolved in dimethyl sulfoxide to a concentration of $2 \mathrm{mg} / \mathrm{ml}$ and diluted to a $100-\mu \mathrm{M}$ concentration in tissue culture media.

Cell culture and reagents. The estrogen-dependent breast cancer cell line, MCF-7 and the estrogen-independent cell line, HTB26 were obtained from the American Type Cell Culture (ATCC, Manassas, VA). Cells were maintained as monolayers in their preferred media at $37^{\circ} \mathrm{C}$ in $5 \% \mathrm{CO}_{2}$. Cells were plated in sterile $96-$ well microtiter plates at $1 \times 10^{5}$ cells $/ \mathrm{ml}$ and incubated for 24 and $72 \mathrm{~h}$ with the above treatments. An 
equal volume of drug vehicle was added representing the controls.

MTT assay. The MTT colorimetric assay was performed to detect tumor cell viability after 24- and 72-h incubation (6). MTT, a tetrazolium dye [3-(4,5-dimethylthiazol-2-yl)-2,5diphenyltetrazolium bromide; thiazolyl blue, Sigma, St. Louis, MO] was added to each well as described previously. Plates were incubated in the presence of MTT dye for $4 \mathrm{~h}$. Mitochondrial dehydrogenase activity reduced the yellow MTT dye to a purple formazan, which was then solubilized with acidified isopropanol and absorbance was read at $570 \mathrm{~nm}$ on an ELISA plate reader.

Annexin V-FITC apoptosis detection kit. (Biovision Inc., Mountain View CA) was used to detect necrotic, early and late apoptotic activity after 18 -h incubation. After treatment as outlined above, cells $\left(1 \times 10^{6}\right)$ were collected and resuspended in binding buffer, and Annexin V-FITC and propidium iodide (PI) were added to each sample and incubated in the dark for 5 min. Annexin V-FITC binding was determined by flow cytometry $(E x=488 \mathrm{~nm}$; Em=530 nm) using an FITC signal detector (FL1) and PI staining by the phycoerythrin emission signal detector (FL2).

Cell cycle analysis (DNA staining). All cells were trypsinized, washed, counted and resuspended to a cell concentration of $10^{5}-10^{6}$ cells per sample. Cells were then centrifuged and $5 \mathrm{ml}$ of $70 \%$ ethanol was added. Cells were then incubated on ice for $2 \mathrm{~h}$. After incubation the cells were centrifuged to remove the ethanol. The cells were then washed once with PBS and resuspended in $0.1 \%$ Triton $\mathrm{X}-100$ solution containing $0.2 \mu \mathrm{g} / \mathrm{ml}$ RNase A. Cells were incubated on ice for 15-30 min and washed with an ample amount of PBS. Cells were resuspended with $1 \mathrm{ml}$ of $0.1 \%$ Triton $\mathrm{X}-100$ solution and $200 \mu 1$ of $1 \mathrm{mg} / \mathrm{ml}$ PI solution was added. Cells were incubated for $15 \mathrm{~min}$ at room temperature before determination of cell cycle by flow cytometry.

Statistical analysis. Determination of statistical significance was performed by analysis of variance (ANOVA) (7). Post hoc comparison of individual concentration means with the control was completed using the Tukey-Kramer Multiple Comparison test (8). All data are reported means and standard deviations.

\section{Results}

MCF cell summary. Inhibition of cell growth was significantly increased at $24(23.3 \pm 1.2 \%, \mathrm{p}<0.001)$ and $72 \mathrm{~h}(45.6 \pm 10.5 \%$, $\mathrm{p}<0.001)$ by catechin. NS398 also exhibited significant reductions in cell growth at $24(17.5 \pm 3.4 \%, \mathrm{p}<0.001)$ and $72 \mathrm{~h}(42.3 \pm 1.3 \%, \mathrm{p}<0.001)$. The combination of catechin and NS398 significantly increased the inhibition of cell growth observed when compared to each agent alone at both $24(42.2 \pm 6.5 \%, \mathrm{p}<0.001)$ and $72 \mathrm{~h}(79.7 \pm 3.4 \%$, $\mathrm{p}<0.001$ ) (Fig. 1). Cellular $\mathrm{G}_{1}$ phase proportions were significantly increased by the addition of NS398 $(76.0 \pm 1.0 \%$, $\mathrm{p}<0.001)$ and catechin alone $(57.7 \pm 0.9 \%, \mathrm{p}<0.05)$ when compared to control $(53.6 \pm 0.7 \%)$. Cells in the S-phase were

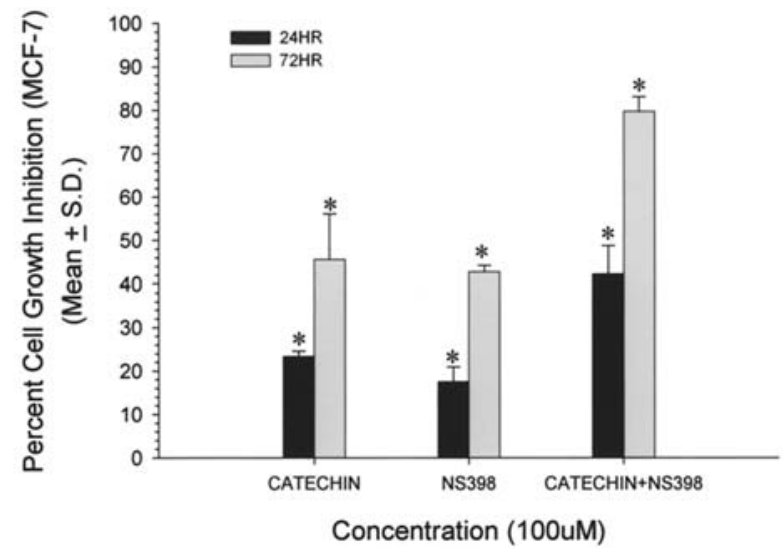

Figure 1. Catechin $(100 \mu \mathrm{M})$ and/or NS398 $(100 \mu \mathrm{M})$ significantly inhibits cell growth in the MCF-7 breast cancer cell line at 24- and 72-h incubation versus the control. Graph depicts the time course. Data shown are means \pm standard deviations. ${ }^{*} \mathrm{p}<0.001$.

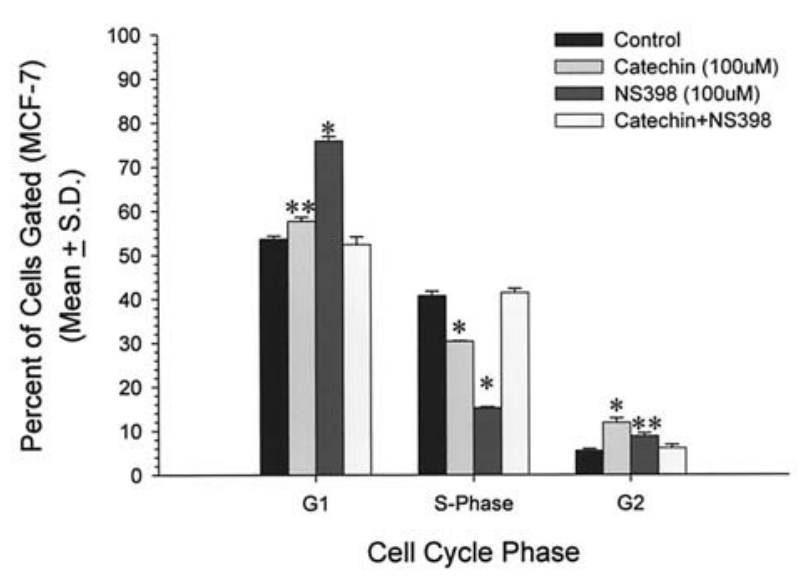

Figure 2. Cell cycle analysis, determined by DNA staining, of the MCF-7 breast cancer cell line treated with catechin $(100 \mu \mathrm{M})$ and/or NS398 $(100 \mu \mathrm{M})$ versus the control. Data shown are means \pm standard deviations. ${ }^{*} \mathrm{p}<0.001$; ${ }^{* *} \mathrm{p}<0.05$.

significantly reduced by the addition of NS398 $(15.3 \pm 0.25 \%$, $\mathrm{p}<0.001)$ and catechin alone $(30.4 \pm 0.12 \%, \mathrm{p}<0.05)$ compared to control $(40.8 \pm 1.0 \%)$. Cells in the $\mathrm{G}_{2}$ phase were significantly increased by the addition of NS398 $(8.8 \pm 0.7 \%, \mathrm{p}<0.05)$ and catechin $(11.9 \pm 1.0 \%, \mathrm{p}<0.001)$ alone when compared to control (5.5 $\pm 0.4 \%$ ) (Fig. 2). Catechin significantly increased apoptosis, both early $(34.9 \pm 15.3 \%, \mathrm{p}=0.004)$ and late $(11.0 \pm 1.3, \mathrm{p}<0.001)$ compared to control $(1.0 \pm 0.2 \%$ and $5.0 \pm 0.5 \%)$. Necrosis $(4.0 \pm 0.7 \%, \mathrm{p}<0.001)$ and late apoptosis $(23.1 \pm 1.6 \%, \mathrm{p}<0.001)$ were also increased by the combination of the 2 agents compared to control $(0.5 \pm 0.1$ and $5.0 \pm 0.5 \%$ respectively) (Fig. 3).

HTB26 cell summary. Inhibition of cell growth was significantly increased at both 24 and $72 \mathrm{~h}$ by catechin $(10.7 \pm 4.9 \%$ and $23.3 \pm 0.2 \%, \mathrm{p}<0.001)$ and NS398 $(27.3 \pm 1.9 \%$ and $56.6 \pm 0.9 \%, \mathrm{p}<0.001)$. As was observed in the MCF7 cells, the combination of catechin and NS398 significantly increased the inhibition of cell growth observed when compared to each agent alone at both $24(43.0 \pm 3.5 \%, \mathrm{p}<0.001)$ and $72 \mathrm{~h}$ $(74.3 \pm 2.7 \%, \mathrm{p}<0.001)$ (Fig. 4). The cellular S-phase proportion 


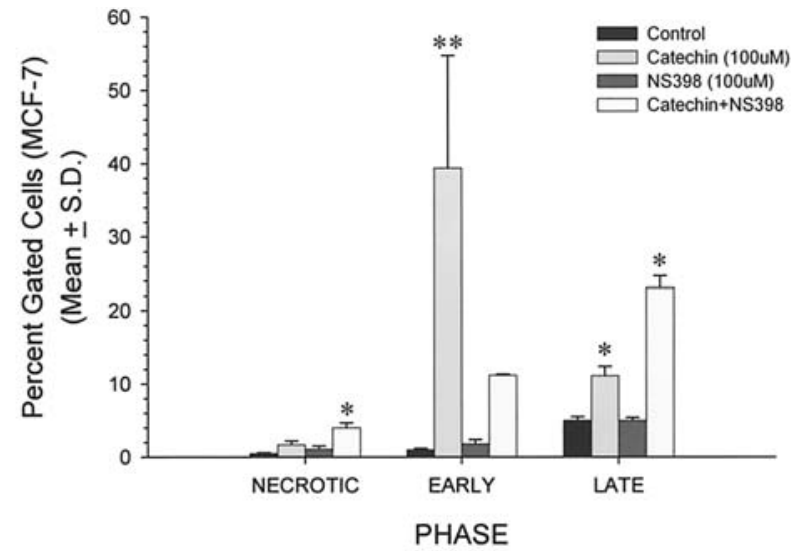

Figure 3. Early and late apoptosis is significantly induced by catechin, while necrosis and late apoptosis were significantly induced by the combination of catechin and NS398. Graph summarizes apoptotic activity in the presence of catechin and/or NS398 versus the control in the MCF-7 breast cancer cell line. Data shown are means \pm standard deviations. ${ }^{*} \mathrm{p}<0.001 ;{ }^{* *} \mathrm{p}=0.004$

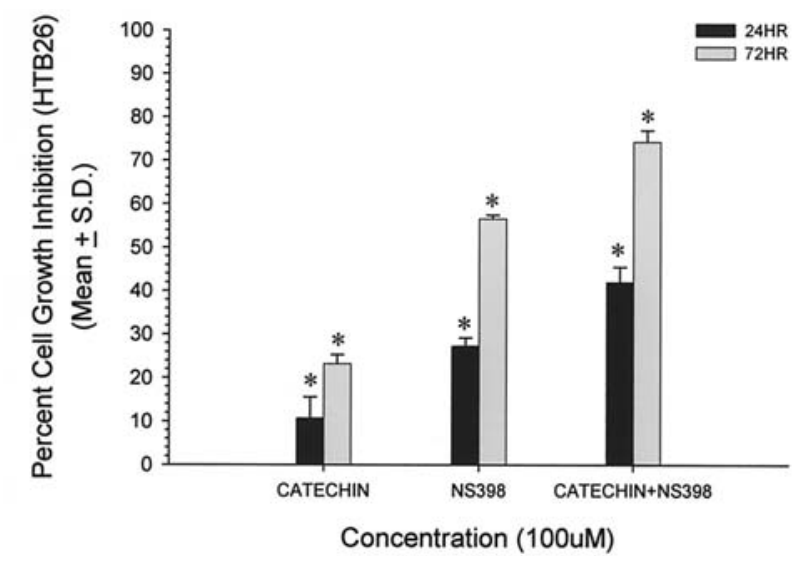

Figure 4. Catechin $(100 \mu \mathrm{M})$ and/or NS398 $(100 \mu \mathrm{M})$ significantly inhibits cell growth in the HTB26 breast cancer cell line at 24- and 72-h incubation versus the control. Graph depicts the time course. Data shown are means \pm standard deviations. ${ }^{*} \mathrm{p}<0.001$.

was significantly decreased by NS398 $(31.2 \pm 0.7 \%, \mathrm{p}<0.01)$ and the combination of the two agents $(33.8 \pm 2.1, \mathrm{p}<0.01)$ when compared to the control $(40.2 \pm 2.7)$. Cells in the $\mathrm{G}_{2}$ phase were significantly increased by NS398 (13.1 \pm 0.4 , $\mathrm{p}<0.001)$ as compared to control $(5.7 \pm 1.7 \%$ ) (Fig. 5). Early apoptosis was significantly increased by the combination of both agents $(5.5 \pm 0.4 \%, \mathrm{p}=0.022)$ when compared to the control $(4.2 \pm 0.6 \%)$. NS398 significantly increased necrosis $(2.3 \pm 0.4 \%, \mathrm{p}=0.016)$, but catechin $(1.0 \pm 0.1 \%, \mathrm{p}=0.035)$ and the combination of the agents $(0.7 \pm 0.1 \%, \mathrm{p}=0.004)$ significantly decreased necrotic activity compared to control. Catechin $(5.7 \pm 0.1 \%, \mathrm{p}<0.001)$ significantly decreased late apoptosis compared to the control $(8.8 \pm 0.8 \%)$. The combination of both agents $(11.8 \pm 0.4 \%, \mathrm{p}<0.001)$ significantly increased late apoptotic activity versus control (Fig. 6).

\section{Discussion}

NSAIDS inhibit both Cox-1 and Cox-2 isoforms but they may inhibit one COX isoform more avidly than the other.

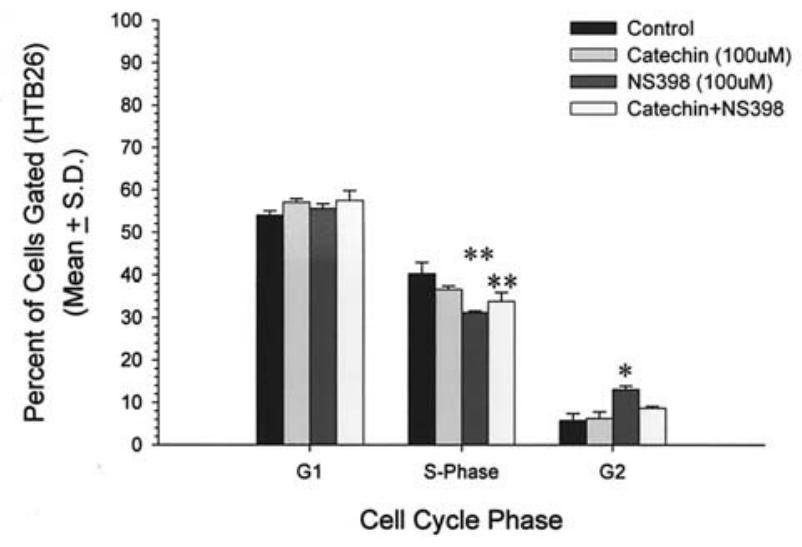

Figure 5. Cell cycle analysis, determined by DNA staining, of the HTB26 breast cancer cell line treated with catechin $(100 \mu \mathrm{M})$ and/or NS398 $(100 \mu \mathrm{M})$ versus the control. Data shown are means \pm standard deviations. ${ }^{*} \mathrm{p}<0.001$; ${ }^{* *} \mathrm{p}<0.01$.

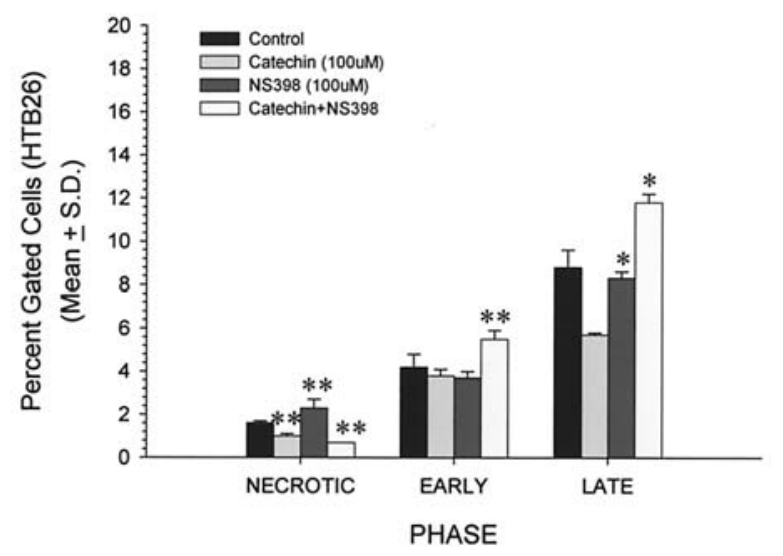

Figure 6. Apoptotic activity, determined by the Annexin V FITC assay, significantly increased early apoptosis when treated with the combination of catechin and NS398. NS398 alone significantly increased necrosis; however, the combination of both inhibitors significantly decreased necrosis. Late apoptosis was significantly reduced by catechin alone, but increased by the combination of catechin and NS398. Graph summarizes apoptotic activity in the presence of catechin and/or NS398 versus the control in the HTB26 breast cancer cell line. Data shown are means \pm standard deviations. ${ }^{*} \mathrm{p}<0.001$; ${ }^{* *} \mathrm{p}<0.05$.

Inhibition of the Cox-1 isoform may cause gastric ulcer formation and bleeding, but NSAIDS highly selective for Cox-2 inhibition may reduce such gastric-related toxicity $(9,10)$. However, other Cox-1 inhibitory derivatives, such as green tea extracts (e.g., catechin), are believed to be unharmful and unsubstantially effect normal tissue (11). Catechins are derived from a variety of natural sources including green tea, grape seeds, wood and tree bark.

Tea polyphenols, such as catechins, have been shown to exhibit cancer-preventive activities in preclinical studies (12). Therefore, its application in the prevention or treatment of breast cancer is plausible. In this study, the anti-proliferative effect of catechin, as a single agent, was more effective on the estrogen-dependent breast cancer cell line, MCF-7 than on the HTB26 breast cancer cell line (estrogen-independent). These results echo our previous study (13) and that of Yang et al, in that catechins may be more effective against specific cancer phenotypes (14). 
Cox-2 is frequently overexpressed in cancer, including tumors of the colon, breast, bladder and prostate $(15,16)$. We have shown that NS398, a specific Cox-2 inhibitor, as a single agent, was more effective in the treatment of bladder and prostate cancer than catechin alone. In the present study, the selective Cox-2 inhibitor, NS398, was highly effective in reducing the proliferative rate of both breast cancer cell lines tested. However, we observed that NS398, as a single agent, was more effective than catechin alone in the treatment of the HTB26 breast cancer cell line at both 24 and $72 \mathrm{~h}$. The MCF-7 breast cancer cell line, when treated with NS398 alone, was equally inhibited by catechin and NS398. Our previous study also demonstrated that catechin and NS398, when combined, exhibited synergistic effects on cell growth in human bladder and prostate cancer (13). In this study, we also observed that with the same two agents, a significant additive effect on the inhibition of cell growth is observed in breast cancer.

The increase in both early and late apoptotic activity seen in the MCF-7 cells with catechin alone indicates that regulation in apoptosis is at least partially responsible for its effect. An increase in early apoptotic activity indicates that the cells are in a static, non-proliferative state, while increases in late apoptotic activity suggest that the cells are in the final stages of the apoptotic cycle and that cell death is imminent. Interestingly, no change in apoptosis (early or late) or necrotic activity was observed in the MCF-7 cells when treated with NS398 alone. However, when the two agents were combined, late apoptotic activity was increased as well as necrotic activity, which would suggest that the mechanism of response is in part, that of cytotoxicity.

Late apoptosis and necrosis were reduced in the HTB26 cell line when treated with catechin alone, whereas necrotic activity was increased with NS398 alone. No changes in early or late apoptotic activity were observed in the HTB26 cells when treated with NS398. When catechin and NS398 were combined, a significant increase in both early and late apoptotic activity was observed.

Michael et al (17), studied the effects of NS398 and/or ciglitazone, a PPAR $\gamma$ ligand, on cell growth, apoptosis and cell cycle in the MDA-MB-231 breast cancer cell line. They reported that when these cells were treated with either NS398 or CGZ, $30 \%$ of cell growth was inhibited after 24-h incubation. However, when the two agents were combined, a synergistic inhibitory effect was observed, $70 \%$. They also observed significant and synergistic increases in the percent of apoptotic cells when treated with NS398 and CGZ, as single agents and when in combination.

The same research group examined the cell cycle effects of NS398 and CGZ. A significant increase of the MDA-MB-231 cells in the $G_{0} / G_{1}$ phase (the phase where the cells are at rest) was observed and a significant decrease of cells entering the S-phase (the phase where the DNA replicates and prepares to divide) and $G_{2} / M$ phase (the phase where DNA replication is completed before cell division occurs) when treated with NS398 or CGZ was noted. However, greater effects were observed when these two agents were combined.

In this study, we also examined the effects of catechin and/or NS398 on cell cycle. We observed a significant increase in the MCF-7 cells entering the $G_{1}$ and $G_{2}$ phases. A significant decrease in the S-phase was seen with treatment with catechin and NS398 as single agents. There were no significant changes observed in cell cycle phase when the two agents were combined. In the HTB26 cell line, no significant effects, as compared to the control group, were observed in the cells entering the $G_{1}$ phase when treated with catechin and NS398, as single agents, or when the two agents were combined. When the HTB26 cells were treated with NS398 alone and in combination with catechin, a significant decrease in S-phase fraction was observed. When compared to the controls, treatment with NS398 alone increased the cells in the $\mathrm{G}_{2}$ phase; however, no changes were observed when the cells were treated with catechin alone or by combining both agents.

VIOXX was the most widely used NSAID ever approved by the FDA and was used to treat osteoarthritis, rheumatoid arthritis, acute pain and menstrual pain. VIOXX was voluntarily withdrawn from the market based on the results obtained from a chemo-preventative study exploring the effects of VIOXX on colorectal polyps. The results of this study showed that patients who received VIOXX (25 mg/daily) for 18 months or more were at a significantly higher risk for stokes and heart attacks than those receiving placebo. However, the data presented herein suggest that Cox-2 inhibitors may potentially play an important role in the treatment of cancer of the breast. Careful screening of patients' personal and family history may reduce the cardiovascular risks that have been associated with the use of Cox-2 inhibitors (18). The use of both Cox-1 and -2 inhibitors as single agents produced significant inhibition of breast cancer in vitro. The combination of the two inhibitors significantly increased the response over that observed with the single agents, suggesting that combination therapy could become a highly effective treatment modality for carcinoma of the breast.

\section{References}

1. Jemal A, Murray T, Ward E, Samuels A, Tiwari RC, Ghafoor A, Feuer EJ and Thun MJ: Cancer Statistics, 2005. CA Cancer J Clin 55: 10-30, 2005.

2. Harris RE, Chlebowski RT, Jackson RD, Frid DJ, Ascenseo JL, Anderson G, Loar A, Rodabough RJ, White E and McTiernan A: Breast cancer and non-steroidal anti-inflammatory drugs: prospective results from the women's health initiative. Cancer Res 63: 6096-6101, 2003.

3. Vona-Davis L, Riggs DR, Jackson BJ and McFadden DW: Antiproliferative and apoptotic effects of rofecoxib on esophageal cancer in vitro. J Surg Res 119: 143-148, 2004.

4. Mohseni H, Zaslau S, McFadden D, Riggs DR, Jackson BJ and Kandzari S: COX-2 inhibition demonstrates potent antiproliferative effects on bladder cancer in vitro. J Surg Res 119: 134-142, 2004.

5. Roberts GE, Vona-Davis L, Riggs DR, Jackson BJ, Mohseni H, Kandzari SJ and McFadden DW: COX-2 inhibition and cancer: experimental findings and clinical correlates. WV Med J 99: 96-101, 2004.

6. Mosmann T: Rapid colorimetric assay for cellular growth and survival: application to proliferation and cytotoxicity assays. J Immunol Methods 65: 55-63, 1983.

7. Dixon WJ and Massey FJ: Introduction to Statistical Analysis. 4th edition. McGraw-Hill, New York, 1983.

8. Ludbrook J: Multiple comparison procedures updated. Clin Exp Pharmacol Physiol 25: 1032-1037, 1998.

9. Cryer B and Feldman M: Cyclooxygenase-1 and cyclooxygenase-2 selectivity of widely used nonsteroidal anti-inflammatory drugs. Am J Med 104: 413-421, 1998.

10. Vainio H and Morgan G: Non-steroidal anti-inflammatory drugs and chemoprevention of cancer. Ann Chir Gynaecol 89: 173-176, 2000 . 
11. Kemberling JK, Hampton JA, Keck RW, Gomez MA and Selman SH: Inhibition of bladder tumor growth by the green tea derivative epigallocatechin-3-gallate. J Urol 170: 773-776, 2003.

12. Chow HH, Cai Y, Alberts DS, Hakim I, Dorr R, Shahi F, Crowell JA, Yang CS and Hara Y: Phase I pharmacokinetic study of tea polyphenols following single-dose administration of epigallocatechin gallate and polyphenon E. Cancer Epidemiol Biomarkers Prev 10: 53-58, 2001.

13. Mohseni-Farivar H, Kandzari SJ, Zaslau S, Riggs DR, Jackson BJ and McFadden DW: Synergistic effects of cox-1 and -2 inhibition on bladder and prostate cancer in vitro. Am J Surg 188: 505-510, 2004.

14. Yang CS, Maliakal P and Meng X: Inhibition of carcinogenesis by tea. Annu Rev Pharmacol Toxicol 42: 25-54, 2002.

15. Fosslien E: Molecular pathology of cyclooxygenase- 2 in neoplasia. Ann Clin Lab 30: 3-12, 2000.
16. Howe LR, Subbaramaiah K, Brown AM and Dannenberg AJ: Cyclooxygenase-2: a target for the prevention and treatment of breast cancer. Endocr Relat Cancer 8: 97-114, 2001.

17. Michael MS, Badr MZ and Badawi AF: Inhibition of cyclooxygenase-2 and activation of peroxisome proliferator-activated receptor- $\gamma$ synergistically induces apoptosis and inhibits growth of human breast cancer cells. Int J Mol Med 11: 733-736, 2003.

18. Bresalier RS, Sandler RS, Quan H, Bolognese JA, Oxenius B, Horgan K, Lines C, Riddell R, Morton D, Lanas A, Konstam MA and Baron JA: Adenomatous Polyp Prevention on Vioxx (APPROVe) Trial Investigators. Cardiovascular events associated with rofecoxib in a colorectal adenoma chemoprevention trial. N Engl J Med 352: 1092-1102, 2005. 